\title{
Manoel Passos Galvao Neto, MD
}

\section{Manoel Galvao Neto ${ }^{1}$}

Published online: 23 May 2019

(C) Springer Science+Business Media, LLC, part of Springer Nature 2019

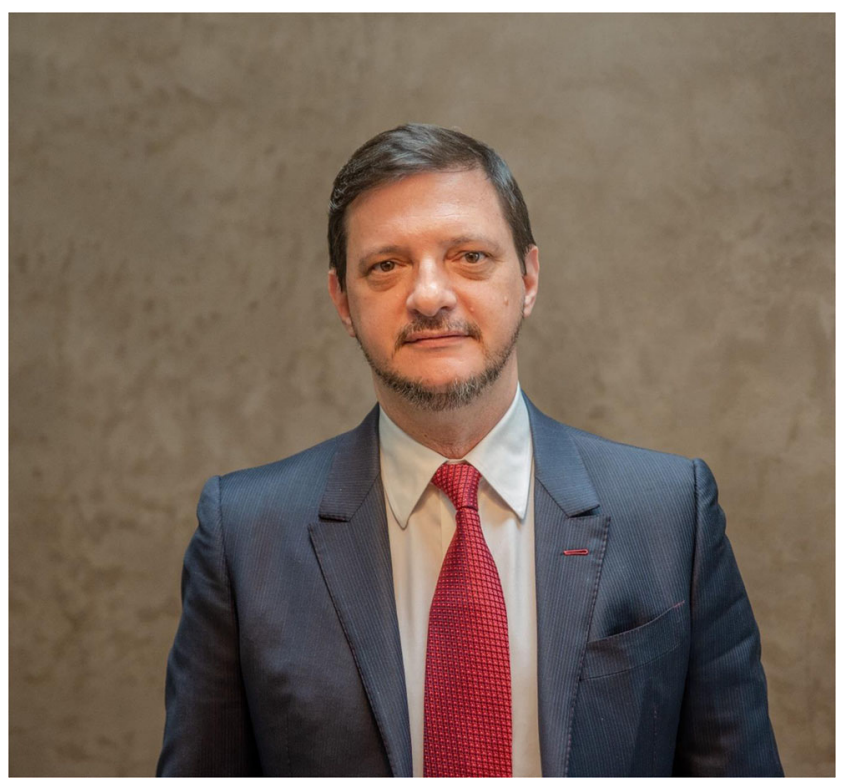

Dr. Manoel Galvao Neto graduated with a degree in Medicine at Bahiana School of Medicine, Bahia, Brazil, in 1989. After finishing a digestive surgery and endoscopy residency program at the 9th of July Hospital in São Paulo, Brazil, he returned to Bahia as an assistant professor of Surgery at Bahia School from 1993 until1998. From 1998 to 2000, he was the Coordinator of the Experimental Surgery Research Group. Inspired by the work of his father, Dr. Manoel Galvao Filho - a surgeon who had pioneered laparoscopic surgery in Brazil — and by his beloved mother, Stella — a leading operating room nurse who delineated his character, behavior, and ethics. Dr. Galvao developed models of video laparoscopic surgery in rats, using conventional instruments that have helped train over a thousand medical students. In 2003,

Manoel Galvao Neto galvaon@gmail.com

$1 \quad$ Sao Paulo, Brazil this work was presented and defended as his Master's Degree thesis at São Paulo University proving that medical students, without any formal surgical training, are capable of performing laparoscopic procedures in rats. Dr. Galvao is also a board-certified specialist in Digestive Surgery by the Brazilian College of Digestive Surgery (CBCD), in Gastroenterology by the Brazilian Federation of Gastroenterology (FBG) and in Digestive Endoscopy by the Brazilian Society of Digestive Endoscopy (SOBED). He is one of only a few clinicians that have all three of these board certifications.

From 1993 to 2000, Dr. Galvao was an instructor for the General Surgery residency program at Cleriston Andrade Hospital in Feira de Santana, Bahia, Brazil. From 1999 to 2000, he worked as an assistant surgeon at São Rafael Hospital, Salvador, Bahia, where he was a surgical proctor and responsible for the training of the clinicians on the esophageal manometry service. At the same time, Dr. Galvao established a busy practice performing thousands of endoscopies, hundreds of laparoscopic surgeries, and at least 50 esophagectomies for Chagas megaesophagus.

In 2001, Dr. Galvao returned to São Paulo to work as the Coordinator of the Esophageal Motility Service at the Diagnoses of America Laboratory. Concurrently, he worked as a researcher and consultant and assisted his industry partners in Brazil in the development of Brazilian hardware and software on esophageal manometry, pHmetry, high-resolution manometry, and $\mathrm{pH}$-impedance which are currently country market leaders. He also developed training models on a novel interactive digital basis, which have been used to train more than 700 Brazilian physicians. The result of this work led to the creation of the Nucleus of Functional Esophageal Evaluation, the NAFAD, dedicated to spreading the current knowledge on the field.

In 2002, Dr. Galvao joined Dr. Almino Ramos and Dr. Manoela Galvao at the Gastro Obeso Center as the scientific coordinator and chief endoscopist on what has become the most successful bariatric surgery unit in Latin America to date with more than 15,000 bariatric procedures performed. At the 
Gastro Obeso Center, in partnership with the industry, Dr. Galvao developed training models for laparoscopic bariatric surgery and multidisciplinary teams that became the gold standards in the field. To date, more than 800 surgeons and many more multidisciplinary team members from Latin America (Brazil included), Portugal, Spain, Japan, and India had been trained on those models.

In 2017, Dr. Galvao left the Gastro Obeso Center to open his own practice with Dr. Eduardo Grecco and Dr. Thiago Souza. The Endovita Institute in Sao Paulo was created and in a brief period of time established itself as the benchmark in the field.

Together with Dr. Josemberg Campos from Recife, Brazil, Dr. Galvao was involved in the creation and development of "Bariatric Endoscopy." In this new field, Dr. Galvao has a number of firsts. In 2000, he was the first to treat bariatric surgery complications using endoluminal approaches. In 2001, he was among the first to insert intragastric balloon. In 2004, Dr. Galvao performed the first endoscopic gastric band removal in South America as well as the first air-filled intragastric balloon implants in 2006. The period of 2004 to 2006 was the "hot years" in the field as endoscopic treatments and tools for complications like septotomy, pneumatic dilation, bariatric stents, and bariatric scissors were developed. Those initial years were also noteworthy for the rapid growth in the number of publications in the field of bariatric endoscopy.

Dr. Galvao's career is also noteworthy for his active participation, often as lead endoscopist, on several "first in human trials." For example, in Chile in 2005, along with Dr. Leonardo Rodriguez, Dr. Galvao participated in the first endoscopic endoluminal duodenal-jejunal bypass. He now serves as a proctor for trials in several countries. From 2006 to 2008, Drs. Galvao and Ramos performed the first Natural Orifice Transluminal Surgery (NOTES) research in animals in Brazil. Shortly thereafter, they performed and then published the second case in the world of a NOTES transgastric cholecystectomy. Furthermore, they also published the largest series of human transvaginal cholecystectomy and the first human transvaginal sleeve gastrectomy procedure performed. From 2008 to 2010, the group focused on metabolic surgery, single port laparoscopy, and laparoscopic greater curvature plication (LGCP) resulting in several more publications.

In 2010 in Chile, he participated in the first-in-man trials of electrical stimulation of the lower esophageal sphincter. In 2011 , he participated as an investigator and proctor on developing the first out of the US series of using endoscopic suturing to revise Roux-en-Y gastric bypasses (RYGB). In 2013, Dr. Galvao helped develop (as an investigator and proctor) the endoscopic sleeve gastroplasty (ESG). He participated in its first-in-human series in Panama and with Dr. Lopez Nava, in the initial European series. This led to several other series across the world. In 2013, Dr. Galvao performed the "first in human" endolumenal duodenal mucosal resurfacing (DMR). He helped develop the technique in Chile and then proctored the REVITA 1 and 2 trials in Europe and other trials in Brazil. In 2017, Dr. Galvao helped successfully launch the ESG clinically in Brazil as the principle proctor and practitioner performing over 2000 cases in less than 2 years. Since 2018, he has participated in the first RCT trial of the endoluminal bowel diversion with magnets. That work is being done in Argentina. He is the clinical proctor for the first RCT trial (MERIT trial) comparing ESG with diet plus intensive lifestyle coaching that will hopefully generate level 1 evidence.

Dr. Galvao's prolific work in the area of endoluminal surgery and his boundless energies to proctor, teach, and publish have resulted in his notoriety worldwide. He has been active as an invited speaker and committee member for several medical societies including SAGES, ASMBS, IFSO, and ASGE. He was a visiting professor at the Chinese University of Hong Kong and the Mayo Clinic. He also was a visiting consultant for the Ministry of Health in Kuwait and UAE. Dr. Galvao serves as a journal reviewer for Obesity Surgery, Surgery for Obesity and Related Diseases (SOARD), Surgical Laparoscopy, Endoscopic Percutaneous Technologies, and Bariatric Times and he has reviewed hundreds of manuscripts. He has published more than 200 peer-reviewed articles and hundreds of book chapters. His Scopus rating is 30 and his Research Gate rates reached 46.13. At least seven of his published papers were cited more than 100 times. The LGCP paper was ranked among the 10 most popular papers published in the Bariatric Times. The Endoscopy journal acknowledged that the first NOTES large series published in 2008 was ranked seventh and one of the papers that significantly raised the impact factor of the journal in 2010. Lastly, as an editor, he published four books in Portuguese, Spanish, and English.

Dr. Galvao is very proud that his career's work resulted in the fact that thousands of patients treated by him or by someone whom he trained had benefited from less invasive options instead of conventional surgical intervention. Additionally, it had led to his reputation as one of if not the most skilled surgical endoscopist in the world. He has been a course director and faculty member in Bariatric Endoscopy courses for a multitude of medical and surgical societies including the International Federation for the Surgery of Obesity (IFSO), American Society for Metabolic and Bariatric Surgery (ASMBS), American Society for Gastrointestinal Endoscopy (ASGE), and Association of Bariatric Endoscopy, as well as the Brazilian societies of endoscopy and bariatric surgery. Hands-on courses were also designed and developed for training centers and universities. At the famous world training center, the Research Institute Against Digestive Cancer (IRCAD) in France, he serves as a faculty member and course director of Bariatric Endoscopy and Surgery courses in the other IRCAD centers in Brazil and Taiwan. 
Since 2013, Dr. Galvao has been assigned as voluntary Clinical Assistant Professor of Surgery at the Herbert Wertheim College of Medicine at FloridaInternational University-FIU (Miami, USA) under the chairmanship of his friend, mentor, and partner, Dr. Natan Zundel and also he has serving asAffiliated Professor of Surgery at the ABC Medicine School (Santo Andre, Sao Paulo, Brazil).

Dr. Galvao is also an active member of several medical societies. In 2016, he was appointed as an Advisory Board Member of ABE. In 2017, he was appointed as the Chairman of the Bariatric Endoscopy Committee of IFSO as well as the Chairman of the Bariatric Endoscopy Nucleus of the Brazilian Society of Endoscopy-SOBED and the Chairman of the Bariatric Endoscopy Nucleus of the Brazilian Society of Metabolic and Bariatric Surgery (SBCBM). In 2015, Dr. Galvao was awarded the "Surgical Innovator Award" by the American Society of Metabolic and Bariatric Surgery. It also marked the first time it was awarded to a nonAmerican.
Dr. Galvao is also active on social media (Facebook, LinkedIn, and Instagram). He helped develop two of the most successful Facebook groups in the field, the International Bariatric Club (IBC) with over 5000 members where he serves as the innovation's director and the High-Tech Surgeons (HTC) with almost 8000 members where he serves as chairman of education and training. Both groups have grown from virtual meetings to well attended annual meetings.

Dr. Galvao Neto states that he does not have a job, but he has a hobby. His passion for his "hobby" is felt across his teaching and the goal to always achieve a new frontier in bariatric endoscopy. He truly believes that "sharing is learning" and we should always strive "for the greater good." To be able to achieve his goals, he has full support of his wife, Sandra, and his two beautiful sons, Bernardo and Theo, of which he is a proud father to both of them.

Publisher's Note Springer Nature remains neutral with regard to jurisdictional claims in published maps and institutional affiliations. 